Article

\title{
Physico-Chemical Surface Modifications of Polyetheretherketone (PEEK) Using Extreme Ultraviolet (EUV) Radiation and EUV-Induced Nitrogen Plasma
}

\author{
Joanna Czwartos*(D), Bogusław Budner ${ }^{D}$, Andrzej Bartnik $\mathbb{D}^{D}$, Przemysław Wachulak ${ }^{(D)}$, \\ Henryk Fiedorowicz and Zygmunt Mierczyk ${ }^{(D)}$ \\ Institute of Optoelectronics, Military University of Technology, 2 Kaliskiego St., 00-908 Warsaw, Poland; \\ boguslaw.budner@wat.edu.pl (B.B.); andrzej.bartnik@wat.edu.pl (A.B.); \\ przemyslaw.wachulak@wat.edu.pl (P.W.); henryk.fiedorowicz@wat.edu.pl (H.F.); \\ zygmunt.mierczyk@wat.edu.pl (Z.M.) \\ * Correspondence: joanna.czwartos@wat.edu.pl
}

Received: 20 September 2020; Accepted: 6 October 2020; Published: 8 October 2020

check for updates

\begin{abstract}
In this work, the effect of extreme ultraviolet (EUV) radiation and the combination of EUV radiation and low-temperature nitrogen plasma on the physico-chemical properties of polyetheretherketone (PEEK) surfaces were presented. The laser-plasma EUV source based on a double gas puff target was used in this experiment to irradiate PEEK surfaces with nanosecond pulses of EUV radiation and to produce low-temperature plasma through the photoionization of nitrogen with EUV photons. The changes in surface morphology on irradiated polymer samples were examined using atomic force microscopy (AFM) and scanning electron microscopy (SEM). Chemical changes of the PEEK surfaces were analysed using X-ray photoelectron spectroscopy (XPS). EUV radiation and nitrogen plasma treatment caused significant changes in the topography of modified PEEK's surfaces and an increase in their average roughness. Strong chemical decomposition, appearance of new functional groups as well as incorporation of nitrogen atoms up to $\sim 17$ at. $\%$ on the PEEK's surface were observed.
\end{abstract}

Keywords: PEEK; surface modifications; surface chemistry; XPS analysis; AFM; extreme ultraviolet (EUV); low-temperature plasma

\section{Introduction}

Polyetheretherketone (PEEK) is a high-temperature, thermoplastic synthetic polymer that belongs to the polyaryletherketones (PAEK) family. The polymer is a very interesting material due to its excellent physico-chemical properties. PEEK has good thermal stability, good chemical resistance [1], and is non-toxic as well as biocompatible; it has also excellent mechanical properties, including strength, stiffness, toughness [2] and is transparent to $X$-rays. Due to these properties, there are multiple industries in which PEEK can be used, including automotive, aerospace, microelectronics, packaging, and, primarily, biomedicine, in which it is considered as a perfect substitute for metallic implant materials (bone surgery, jaw surgery, orthopedics) [3,4]. Despite the advantages mentioned, PEEK-similarly to many other organic polymers [5-10] - shows low bioactivity, is hydrophobic, and lacks surface-active functional groups that promote protein adsorption, cell adhesion, and proliferation. This is why PEEK, when implanted, shows limited integration with osseous tissues. It is the factor which strongly limits its clinical application. Thus, appropriate physico-chemical modification of the PEEK surface, and its micro- and nanostructuring, can improve its bioactivity. Many techniques were used for PEEK 
modification, including chemical surface treatment [11,12], laser processing [13,14], and the most popular, which seems also to be the most universal—surface plasma treatment $[15,16]$. The effect of the exposure to plasma induces a variety of changes on polymer surfaces. These include surface ablation or etching, crosslinking or chemical changes such as the incorporation of atoms or various polar functional groups. One of the major results of plasma polymer treatment is the changes in surface topography that affect roughness, wettability, and, consequently, adhesion and bioactivity. Examination of the influence of plasma treatment using different plasmas on PEEK physico-chemical parameters and its biocompatibility has been the subject of numerous studies. For example, Waser-Althaus et al. [17] observed that oxygen and ammonia plasma treatment of PEEK induced strong chemical changes (i.e., oxidation or implantation of surface-amino groups) and topography changes (i.e., nanostructuring). What is also important is that it supported the osteogenic differentiation of human mesenchymal stem cells (adMSC). On the other hand, Novotna et al. [18] modified the surface of PEEK using argon plasma and observed that exposure to plasma resulted in the improvement of PEEK's wettability and caused changes in its surface morphology and chemistry. The changes in PEEK's surface, induced this way, significantly enhanced mouse fibroblasts and human osteoblasts adhesion, proliferation, and also metabolic activity. Other studies exhibit that PEEK plasma treatment can considerably improve its adhesive features, which is very important when applying various organic or non-organic coatings [19-22].

In this study, an alternative technique of surface modification, using intense nanosecond pulses of extreme ultraviolet (EUV) for PEEK foils irradiation and the EUV irradiation combined with a low-temperature nitrogen plasma treatment, was presented. Polymer surfaces exposure to EUV radiation results in surface ablation, surface geometry changes, and modification of their chemical structure. Moreover, additional usage of the low-temperature plasma induced by the EUV beam in a gas injected into the area surrounding the irradiated polymer surface causes the incorporation of new functional groups into the polymer surface. In this paper, the detailed chemical analysis of modified PEEK foils carried out based on high-resolution XPS spectra analysis is presented. Changes in surface morphology were examined using atomic force microscopy (AFM) and scanning electron microscopy (SEM).

\section{Materials and Methods}

\subsection{Modifications of PEEK Films}

In the experiment, the amorphous PEEK films with a thickness of $0.075 \mathrm{~mm}$ (Goodfellow Cambridge Ltd., Huntingdon, UK) were modified. The modifications were performed using a laser-produced plasma (LPP) EUV source dedicated to the surface processing of polymers [23]. The source was developed in our laboratory. It is based on a gas-puff target system and a compact Nd:YAG laser producing 4 ns laser pulses with maximum energy up to $0.8 \mathrm{~J}$ (NL 303 HT, EXPLA, Vilnius, Lithuania) and $10 \mathrm{~Hz}$ repetition rate. In the experiment, the target was formed as a result of a pulsed injection of a xenon jet into a hollow stream of helium (Xe/He target) with the use of an electromagnetic valve system equipped with a double nozzle set-up. The laser beam focused on the Xe stream created the high-temperature plasma. In the experiment, focusing conditions and plasma parameters were adjusted in order to obtain a maximum intensity in extreme ultraviolet. The EUV radiation was focused using a gold plated grazing incidence ellipsoidal collector (RITE s.r.o., Dolni Břežany, Czech Republic). The collector allowed for effective focusing of Xe plasma radiation within the wavelength range of $\lambda=9-70 \mathrm{~nm}$-Figure 1 . 


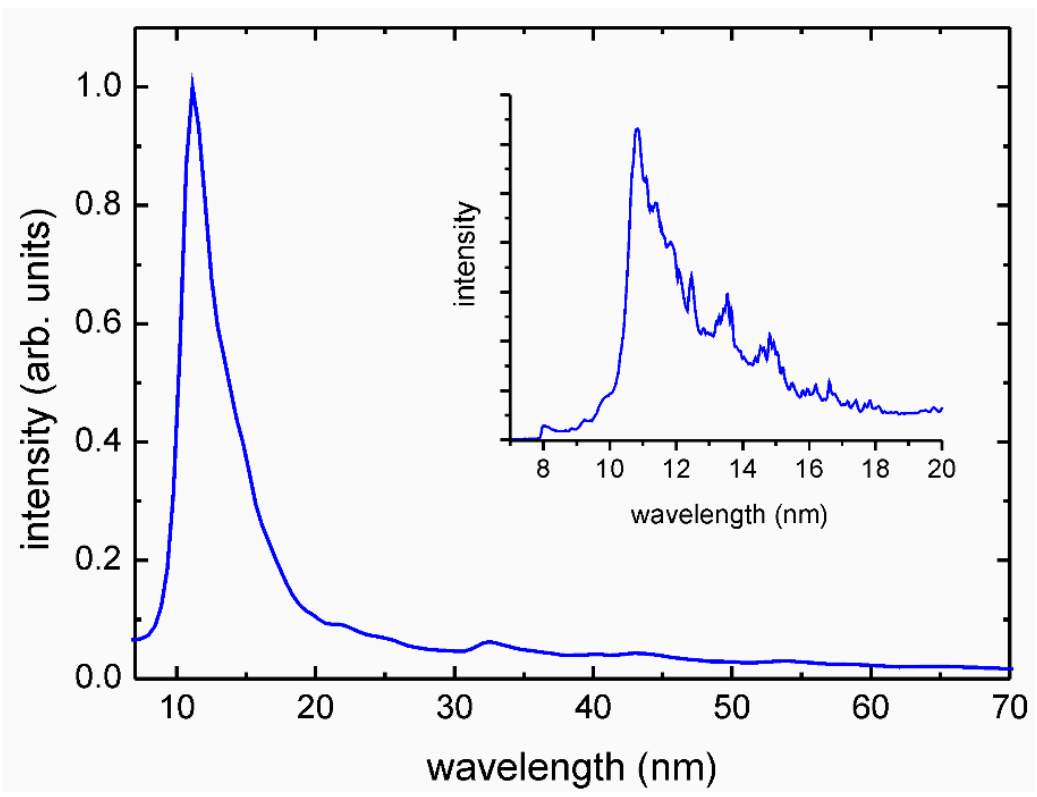

Figure 1. The spectrum of the extreme ultraviolet (EUV) radiation emitted from laser-produced plasma (LPP) Xe plasmas and focused by the ellipsoidal collector. In the inset, the most intense part of the spectrum, measured with higher resolution, is presented.

The maximum intensity was in a relatively narrow spectral region centered at $\lambda \approx 11 \mathrm{~nm}$. The EUV fluence in the focal plane of the collector was about $60 \mathrm{~mJ} / \mathrm{cm}^{2}$ at the centre of the focal spot. A part of the EUV beam could be used for photoionization of the nitrogen gas injected through the auxiliary gas-puff valve into the region of the focal spot, perpendicularly to an optical axis of the EUV collector. Photoionization of the gas by the intense EUV radiation pulse resulted in a low-temperature plasma formation. Spectral measurements of the nitrogen plasmas, performed in the wide wavelength range (EUV-UV-VIS), revealed the presence of single charged atomic ions $\left(\mathrm{N}^{+}\right)$, molecular ions $\left(\mathrm{N}_{2}{ }^{+}\right)$, and also neutral atoms $(\mathrm{N})$ and molecules $\left(\mathrm{N}_{2}\right)$. A detailed description of the EUV-induced plasmas can be found elsewhere [24]. Nitrogen gas density in the interaction region was controlled by the adjustment of the gas-puff valve opening time [25]. The PEEK samples were mounted on the XYZ movable stage, located $3 \mathrm{~mm}$ from the focal spot and irradiated with 40 and 150 pulses at a $10 \mathrm{~Hz}$ repetition rate. The EUV irradiation of the polymer films was carried out without (a) and with (b) nitrogen presence-Figure 2. In the case of using the nitrogen, a part of the radiation was absorbed, ionizing the gas. The second part reached the polymer surface. This way, the dual action of plasma and the EUV radiation on the material surface was possible.

The modified area on the polymer's surface was circle-like shaped with a diameter of $\sim 1.9 \mathrm{~mm}$. Such a size of the modified surface was large enough for morphological examinations of the PEEK samples, performed using an atomic force microscope (AFM). For XPS studies to be performed, the area of $\sim 0.5 \times 0.7 \mathrm{~cm}^{2}$ (7 spots in total) was modified. 


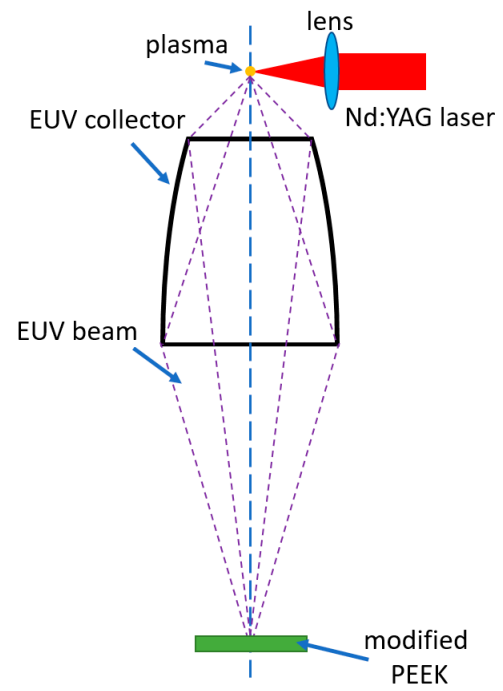

(a)

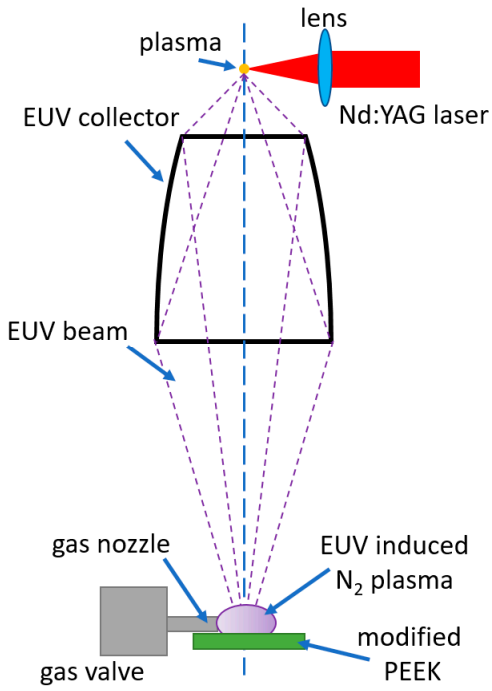

(b)

Figure 2. The scheme of experimental arrangement: (a) polyetheretherketone (PEEK) sample modified with EUV radiation, (b) PEEK sample modified with EUV radiation and nitrogen plasma.

\subsection{Surface Analysis of Modified PEEK Surfaces}

\subsubsection{Atomic Force Microscopy (AFM) and Scanning Electron Microscopy (SEM)}

Surface morphology, profile, and roughness of pristine and modified PEEK samples were examined using an AFM (NT-MDT Spectrum Instruments, Moscow, Russia). The measurements were carried out at ambient conditions in a semi-contact mode using a golden silicon AFM probe (NSG 10, NT-MDT Spectrum Instruments, Moscow, Russia) featuring a pyramidal tip with a curvature radius of $\sim 10 \mathrm{~nm}$. The cantilever of the probe was characterized by a force constant range from 3.1 to $37.6 \mathrm{~N} / \mathrm{m}$ and a resonant frequency range of $140-390 \mathrm{kHz}$. The scan size of the topographies collected was $50 \mu \mathrm{m} \times 50 \mu \mathrm{m}$ with a resolution of 256 points per line. Three different regions were scanned on each sample and the average surface roughness was calculated using Image Analysis software (version-3.5 provided by NT-MDT Spectrum Instruments.

SEM scans were captured with a scanning electron microscope (Quanta FEG250, FEI, Hillsboro, OR, USA). The acceleration voltage was $20 \mathrm{kV}$. All samples studied were deposited with a platinum layer of $8 \mathrm{~nm}$ thickness. The platinum layer was deposited from a platinum target (99.999\%) by means of a sputter coater (Leica EM ACE200, Leica Microsystems, Wetzlar, Germany).

\subsubsection{X-ray Photoelectron Spectroscopy (XPS)}

Chemical analysis of the PEEK surfaces modified with 40 and 150 pulses of EUV radiation and a combination of EUV radiation and low-temperature nitrogen plasma was performed using X-ray photoelectron spectroscopy (XPS). The spectrometer XPS (Prevac, Rogów, Poland) used was equipped with the SCIENTA R3000 analyser (VG Scienta, Uppsala, Sweden) and an X-ray lamp with the $\mathrm{Al} \mathrm{K} \mathrm{K}_{\alpha}$ anode (Prevac, Rogów, Poland). During the measurements, the pressure in the ultra-high vacuum chamber of the XPS system was approximately $3 \times 10^{-9}$ mbar. Before the XPS examination, the non-modified PEEK foil was cleaned using ethyl alcohol, while the modified PEEK samples were examined without any cleaning. A thorough chemical analysis, i.e., high-resolution spectra in the narrow ranges of binding energy with a $40 \mathrm{meV}$ step and pass energy of $100 \mathrm{meV}$ for each band: C1s (294-282 eV), N1s (404.5-395.5 eV), and O1s (537-528 eV), were recorded. The peaks associated with the C1s, N1s, and O1s bands were fitted using CasaXPS software (version 2.3.23, www.casaxps.com). The background of linear type and Gaussian-Lorentzian (GL) line shape (GL 50 for C1s, GL 60 for N1s, 
and GL 55 for O1s) were fitted for all these bands. All XPS spectra measured were shifted in such a way that the maximum of the $\mathrm{C}-\mathrm{C}=\mathrm{C}$ peak (refers to carbon ring in PEEK's mer unit) was at $284.8 \mathrm{eV}$.

\section{Results and Discussion}

\subsection{Morphological Changes on PEEK Surfaces}

EUV irradiation of untreated polymer foils results in the formation of different structures on their surfaces. The character of the topography obtained, i.e., the shape of the micro- and/or nanopatterns formed, their size, height, or directionality, strongly depends on the number of pulses used, fluence, and the physico-chemical properties of the pristine polymer, i.e., the material sensitivity, ablation threshold value, thermal conductivity, glass transition temperature, etc. In this experiment, the AFM was employed to examine the morphology of the PEEK surface before and after EUV irradiation. As simultaneous treatment of PEEK surfaces by EUV radiation and nitrogen plasma resulted in the formation of the same pattern as in the case of only PEEK-treated EUV radiation, the presentation of the results for that case was omitted. Figure 3 shows the AFM topographies of the non-modified PEEK surface and the PEEK surface modified with 40 and 150 EUV pulses with a scan size of $50 \mu \mathrm{m} \times 50 \mu \mathrm{m}$ and with their corresponding SEM images in a similar scale.
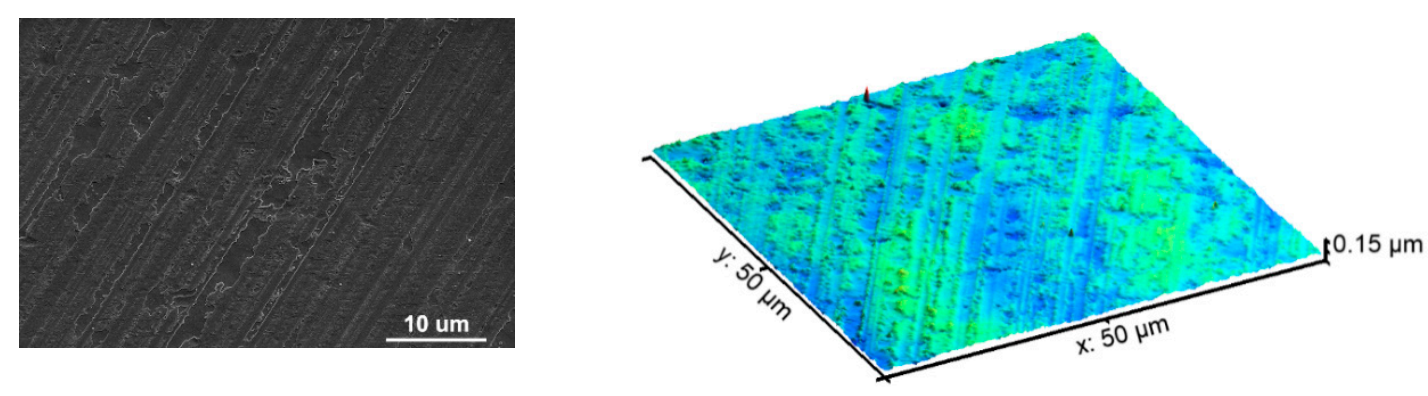

(a)
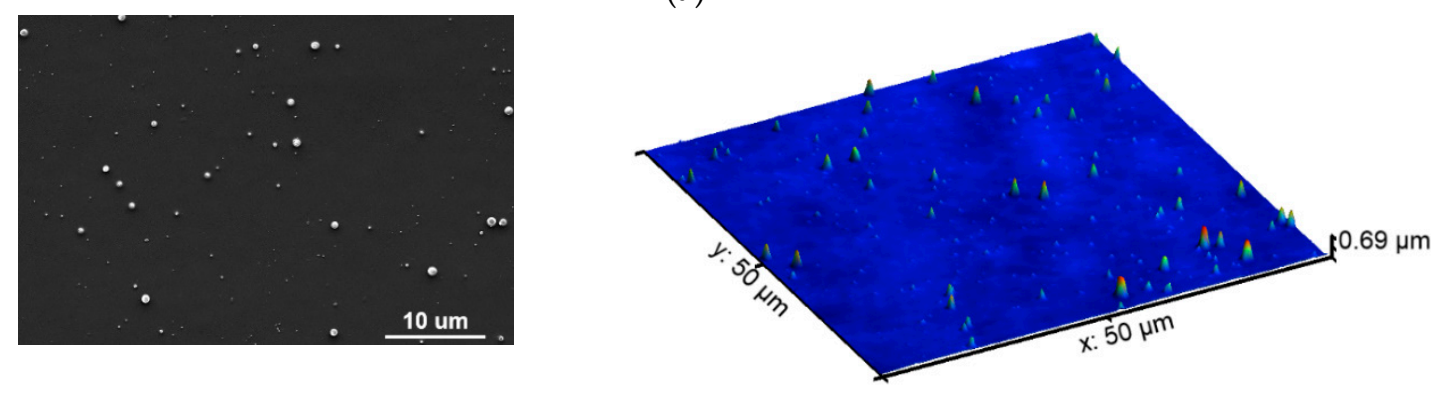

(b)
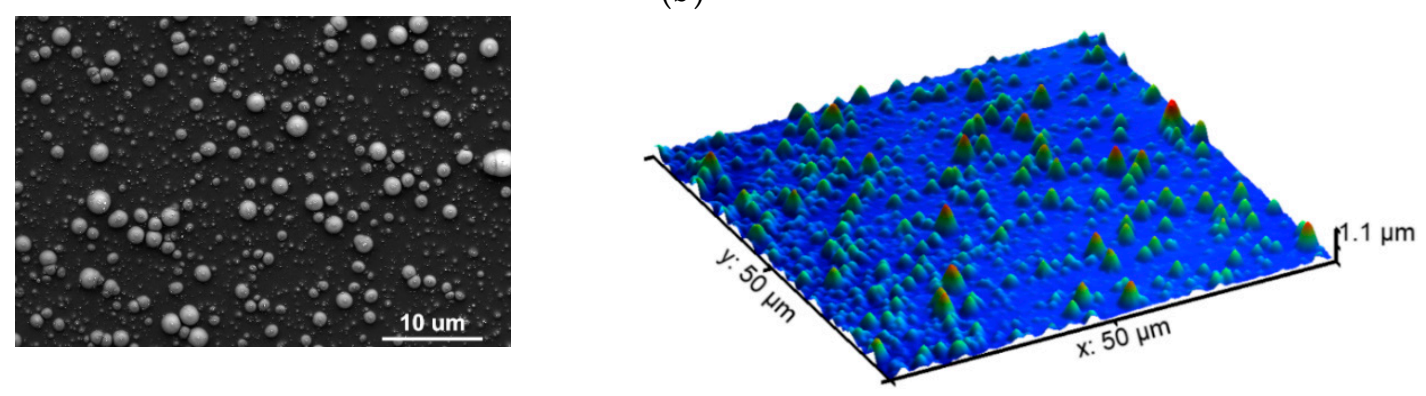

(c)

Figure 3. SEM images compared with the AFM topographies of (a) untreated PEEK, (b) PEEK treated with 40 EUV pulses, (c) PEEK treated with 150 EUV pulses. 
As shown in the Figure 3, the unmodified PEEK surface originally had specific subtle trails in the form of grooves and irregularities running parallel to the foil's edge in one direction. These trails most likely reflected irregularities on the surface of the mold or roller with which the PEEK foil got in contact during the production process. The average roughness calculated for this sample was $16.2 \pm 2.0 \mathrm{~nm}$. The height of the sample's original structures measured using cross-section analysis of the AFM topographies (where the profile of the PEEK structure was obtained along with a single, selected line), did not exceed $60 \mathrm{~nm}$-Figure 4 (blue line).

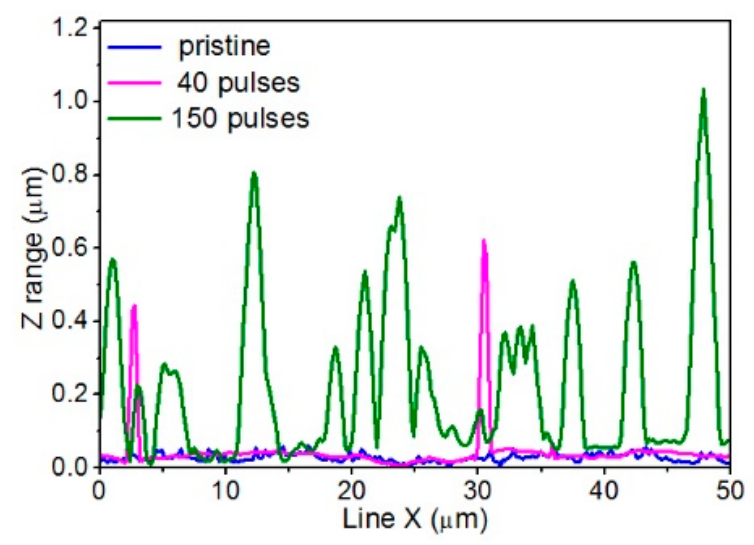

Figure 4. Cross-section profiles obtained from the AFM topographies along the selected line for untreated PEEK and PEEK treated with 40 and 150 EUV pulses, respectively.

The topography of PEEK treated with 40 EUV pulses changed significantly compared to the pristine PEEK. The specific trails running in one direction were not there anymore, and the surface was clearly ablated. Moreover, randomly located micro- and nanometer-scale features appeared on the surface. The larger features were conical in shape as evidenced by not only AFM scans but also the cross-section profiles obtained from the AFM topographies (see Figure 4-pink purple line). Their maximum diameter at the base was $\sim 1 \mu \mathrm{m}$ and the heights did not exceed $700 \mathrm{~nm}$. Diameters of the smallest structures on the surface were approximately $100 \mathrm{~nm}$. The average roughness measured for this sample increased, compared to the non-modified one, and was $45 \pm 5 \mathrm{~nm}$.

The number and size of these features on the PEEK surface treated with 150 EUV pulses significantly increased. The maximum diameter of the conical structures at the base even exceeded $3 \mu \mathrm{m}$, while the diameters of the smallest structures were still $\sim 100 \mathrm{~nm}$. The heights of the cones on the surface exceeded $1 \mu \mathrm{m}$ in some cases. The average roughness for this sample almost doubled compared to PEEK modified with 40 EUV pulses and reached $115 \pm 11 \mathrm{~nm}$.

Therefore, the surface density of the features as well as the average roughness of the foil increased with the number of EUV pulses.

The formation of conical structures on the PEEK surface is probably connected with the shielding effects related to local enrichments of photofragments or material impurities having a higher ablation threshold than the polymer [26] Smaller features with diameter about 100-200 nm, which are visible both on the surface of PEEK and at the top of the cones, may arise as a result of hydrodynamic instabilities, as suggested by Bauerle [26], and also be responsible for the formation of the conical structures [26-28]. Similar conical structures on the surfaces of various polymers (PET, PMMA, PTFE, FEP) irradiated with EUV pulses have been already observed by our group in previous experiments [29-32]. The same structures were also observed by other authors who irradiated surfaces of various organic polymers, including PC, PI, PET, nylon, etc., with UV light from excimer lasers [27,33]. 


\subsection{Chemical Analysis of Pristine and Modified PEEK Surfaces}

In order to conduct a thorough chemical analysis of XPS spectra obtained for modified PEEK surfaces, first the reference material, i.e., non-modified PEEK, was examined. For the non-modified PEEK's C1s and O1s bands registered, the model of peaks corresponding to its chemical structure (Figure 5) was developed.<smiles>COc1ccc(C(=O)c2ccc(Oc3ccc(C)cc3)cc2)cc1</smiles>

Figure 5. Chemical structure of PEEK's mer unit.

Three peaks were modeled for the C1s band-Figure 6a. The first peak at $284.8 \mathrm{eV}$ (FWHM $1.3 \mathrm{eV}$ ) represents the $C-C=C$ structure in carbon rings (carbon atoms marked as 1 on Figure 5 ), the second peak at $286.4 \mathrm{eV}$ (FWHM 1.6-1.7 eV) represents the C-O-C group (carbon atoms marked with 2 on Figure 5) and the third one at $286.7 \mathrm{eV}$ (FWHM 1.7-1.8 eV) represents $\mathrm{C}=\mathrm{O}$ (carbon atoms marked with 3 on Figure 5). Two peaks were modeled for the O1s band: the one at $531.1 \mathrm{eV}$ (FWHM $1.5 \mathrm{eV}$ ) that represents the $\mathrm{O}^{*}=\mathrm{C}$ group and another one at $533.2 \mathrm{eV}(\mathrm{FWHM} 1.6 \mathrm{eV})$ that represents the $\mathrm{C}-\mathrm{O}^{*}-\mathrm{C}$ group-Figure $6 b$.

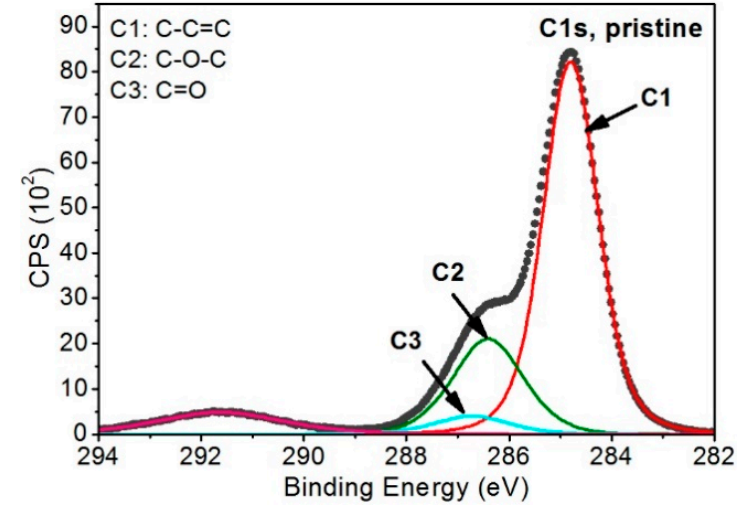

(a)

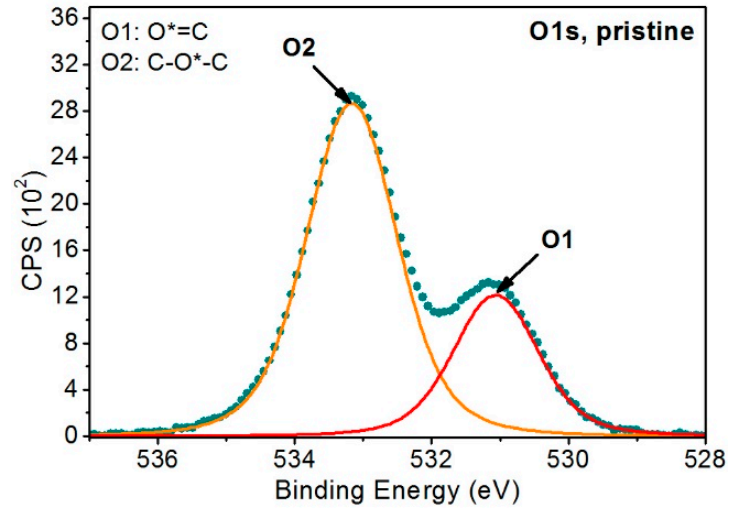

(b)

Figure 6. XPS spectra of non-modified PEEK: (a) C1s band, (b) O1s band.

Carbon and oxygen bands in the model were related to each other so that the amount of oxygen single bonded with carbon was twice as little as the amount of carbon single-bonded with oxygen, which is in accordance with the chemical structure of the PEEK mer unit. A similar relation was set up for the peaks coming from carbon atoms double-bonded with oxygen, and the content of the peaks is equal, according to the material's chemical structure. Moreover, $\pi-\pi^{*}$ peak was introduced to the model, corresponding to the presence of carbon rings in the polymer's structure. The model developed this way appropriately describes the unmodified PEEK. 
The model developed was then used for the analysis of the spectra of the samples treated with EUV radiation and EUV radiation in the presence of nitrogen. Three variants of PEEK surface modification were used: (1) treatment of the PEEK surface with 40 and 150 EUV pulses, (2) treatment of the PEEK surface with 40 and 150 EUV pulses in the presence of nitrogen with density determined by the valve opening time of $300 \mu \mathrm{s}$, (3) treatment of the PEEK surface with 40 and $150 \mathrm{EUV}$ pulses in the presence of nitrogen with density determined by the valve opening time of $350 \mu$ s.

XPS examination of the first variant showed the presence of oxygen and carbon atoms as well as deep changes of the C1s and O1s peaks' envelopes. For the second and third variants, apart from the presence of oxygen and carbon, the high content of nitrogen in the modified samples' surface was observed, as a result of the interaction of ionized nitrogen on the PEEK surface.

Figure 7 shows the results of the XPS examination analysis for the first variant of the PEEK sample irradiated with 40 and 150 EUV pulses.

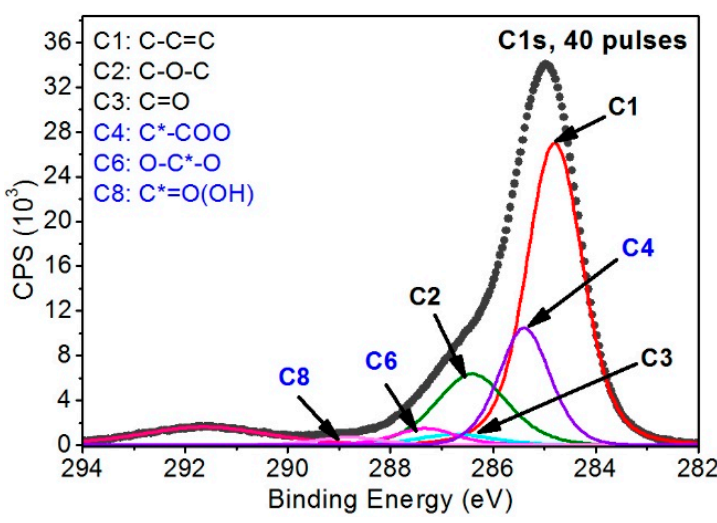

(a)

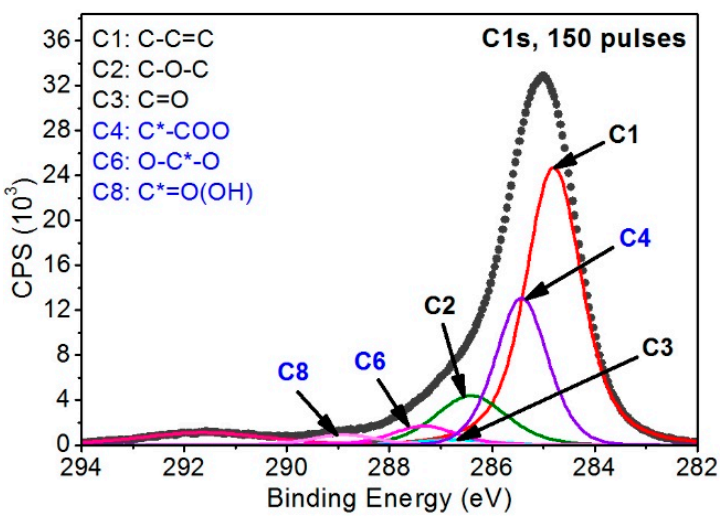

(c)

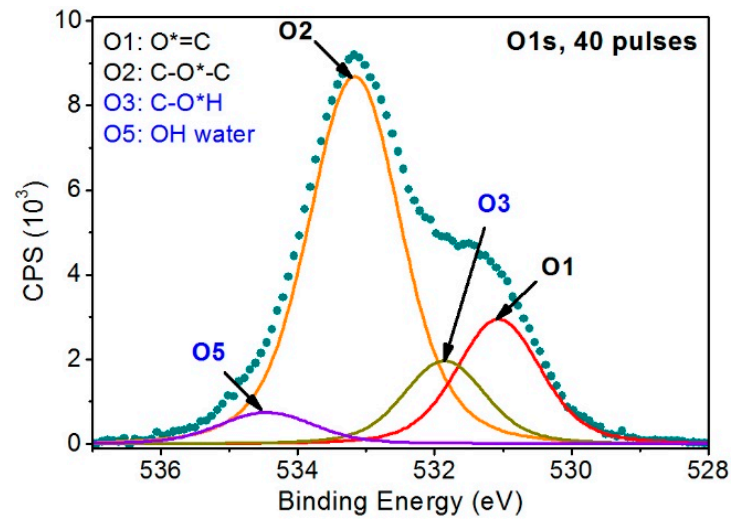

(b)

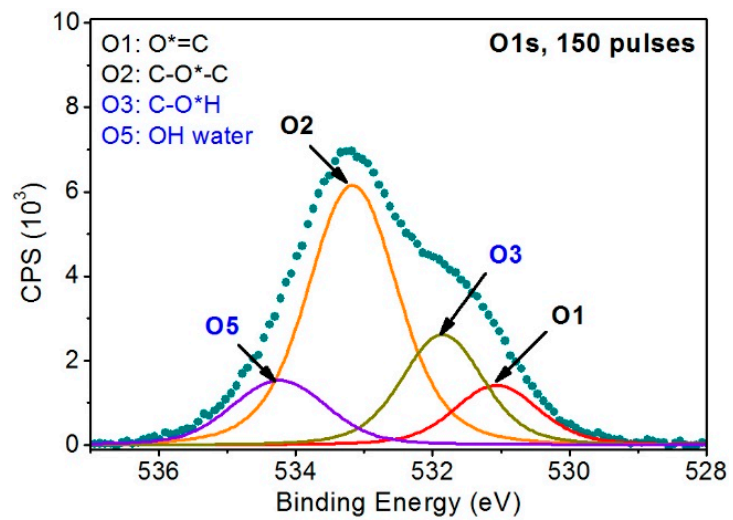

(d)

Figure 7. XPS spectra of modified PEEK: (a) with 40 EUV pulses-C1s band, (b) with 40 EUV pulses-O1s band, (c) with 150 EUV pulses-C1s band, (d) with 150 EUV pulses-O1s band.

Due to the dramatic change in the shape of the C1s and O1s peaks' envelopes of the samples modified, not only peaks from the pristine PEEK model, but also other peaks describing changes of the polymer resulting from EUV irradiation, were added. Therefore, three additional peaks corresponding to functional groups were introduced to the $\mathrm{C} 1 \mathrm{~s}$ band, which probably formed during the breaking of bonds between atoms coming from polyetheretherketone mer units:

- $\quad \mathrm{C}^{*}-\mathrm{COO}(\mathrm{C} 4)$ - at $\sim 285.4 \mathrm{eV}$ (FWHM 1.3-1.4 eV)—corresponds to secondary chemical shifts. This is most likely a result of breaking the bonds between atoms marked as 3 and 2 (Figure 5), linking vicinal carbon rings. 
- $\quad \mathrm{O}-\mathrm{C}^{*}-\mathrm{O}(\mathrm{C} 6)$-at $\sim 287.3 \mathrm{eV}$ (FWHM 1.4-1.5 eV)—is most likely the effect of breaking the bond between the carbon marked as 3 (Figure 5) and the carbon ring. The empty bond is then filled with an oxygen atom.

- $\quad \mathrm{C}^{*}=\mathrm{O}(\mathrm{OH})(\mathrm{C} 8)$ - at $\sim 288.8-288.9 \mathrm{eV}(\mathrm{FWHM} \sim 1.5 \mathrm{eV})$-is most likely formed as a result of breaking the bond between the atom marked as 3 (Figure 5) and the carbon ring and then attaching the $\mathrm{OH}$ group to the carbon atom marked as 3 .

As far as the O1s band is concerned, it was filled with the following peaks:

- $\quad \mathrm{C}-\mathrm{O}^{*} \mathrm{H}(\mathrm{O} 3)$ - at $~ 531.9 \mathrm{eV}$ (FWHM 1.4-1.5 eV)—is most probably associated with the presence of $\mathrm{OH}$ groups within the chemical structure of the modified PEEK, as this peak corresponds to the peak $\mathrm{C} 8$ and fills the envelopes of the $\mathrm{O} 1 \mathrm{~s}$ band between $\mathrm{O} 1$ and $\mathrm{O} 2$ peaks modeled for the unmodified PEEK material.

- $\mathrm{OH}$ (water) (O5)—534.2-534.5 eV (FWHM 1.6-1.7 eV)—this peak most likely comes from $\mathrm{OH}$ groups of the water adsorbed on the sample surface after taking it out from the vacuum.

The introduction of the peaks given above allowed for an appropriate filling of C1s and O1s bands' envelopes of the samples modified. The analysis also assumed that the introduced peaks, which were taken from the pristine PEEK, would keep their parameters (i.e., peak position, FWHM). Additional peaks added were associated with the most probable changes in the chemical structures of the material exposed to EUV radiation. Regarding variants 2 and 3 of the sample modifications carried out using EUV radiation in nitrogen presence, it was ascertained that it is necessary to introduce another seven peaks to the $\mathrm{C} 1 \mathrm{~s}, \mathrm{O} 1 \mathrm{~s}, \mathrm{~N} 1 \mathrm{~s}$ bands, related to the incorporation of nitrogen atoms to the PEEK surface (Figure 8):

- $\quad \mathrm{C}^{*}-\mathrm{N}(\mathrm{C} 5)$-at 286.3-286.4 eV (FWHM $1.5 \mathrm{eV}$ )—peak related to the incorporation of nitrogen atoms into the PEEK structure as a result of breaking bonds of the carbon marked as 2 or 3 (Figure 5) and introducing nitrogen atoms in that place.

- $\quad \mathrm{N}-\mathrm{C}^{*}=\mathrm{O}(\mathrm{C} 7)$ - at $288.4-288.5 \mathrm{eV}(\mathrm{FWHM} 1.5 \mathrm{eV}$ )—is formed most likely as a result of carbon bond breaking (carbon marked as 3 -Figure 5) and filling it with a nitrogen atom.

- $\quad C^{*}-\mathrm{OON}($ C9)—at 289.3-289.5 eV (FWHM $1.5 \mathrm{eV}$ )—due to a huge chemical shift of this peak relative to the $\mathrm{C} 1$ peak, it was assumed that this structure most probably contains two oxygen atoms and a single nitrogen atom. The proof for the presence of this peak is a huge change in the shape of the C1s' envelope around the binding energy values of 289.3-289.5 eV. Such change was not observed for the samples treated with EUV radiation only. Taking into account the location of this peak on the energy axis and the fact that the oxygen content in the samples modified with EUV irradiation in the presence of nitrogen does not exceed the content in the samples modified with EUV irradiation alone, there is a low probability that this peak represents structures containing oxygen only.

- $\quad \mathrm{N}^{*}-\mathrm{C}(\mathrm{N} 1)$-at 399.2-399.4 eV (FWHM 1.9-2.1 eV)—peak corresponds to C5

- $\quad \mathrm{N}^{*}-\mathrm{C}=\mathrm{O}(\mathrm{N} 2)$-at 400.0-400.2 eV (FWHM 1.8-1.9 eV) —peak corresponds to C7

- $\quad \mathrm{N}^{*}-\mathrm{x}(\mathrm{N} 3)$-at $400.8-400.1 \mathrm{eV}$ (FWHM 1.8-2.1 eV)—it is difficult to interpret this peak unambiguously. However, taking into account the measurements of the reference polymers containing nitrogen atoms, such as PU, Kapton, nylon, confronted with the data taken from literature, it can be assumed that these are nitrogen atoms bonded with carbon atoms which form chemical bonds with at least two oxygen atoms.

- $\quad \mathrm{N}-\mathrm{C}=\mathrm{O}^{*}(\mathrm{O} 4)$ - at 532.1-532.2 eV (FWHM 1.5-1.6 eV)—peak corresponds to C7. 


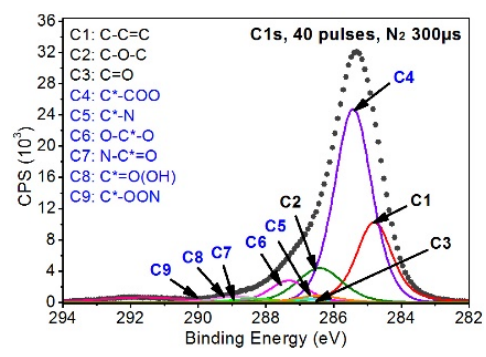

(a)

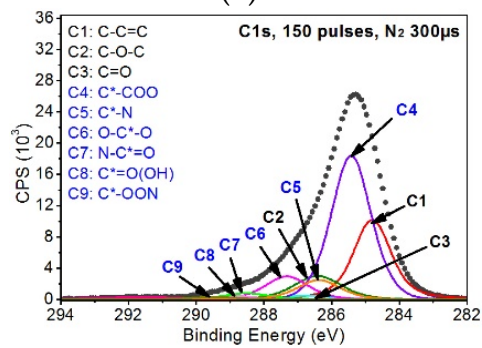

(d)

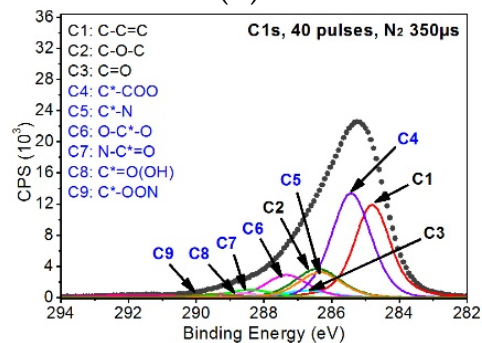

(g)

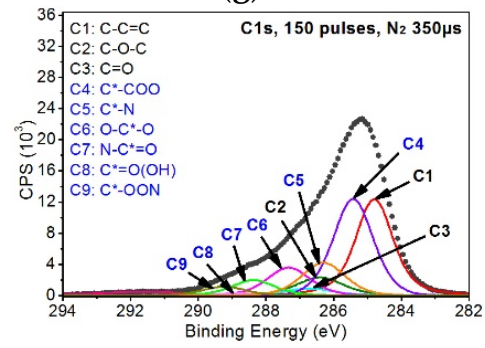

(j)

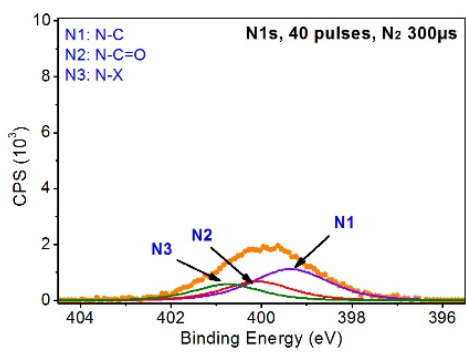

(b)

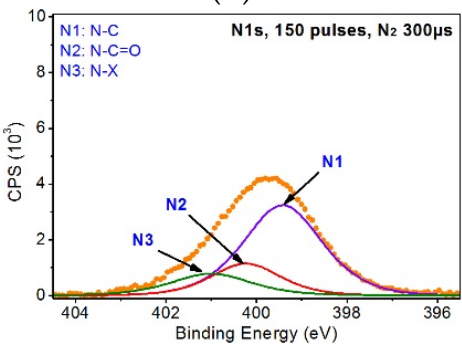

(e)

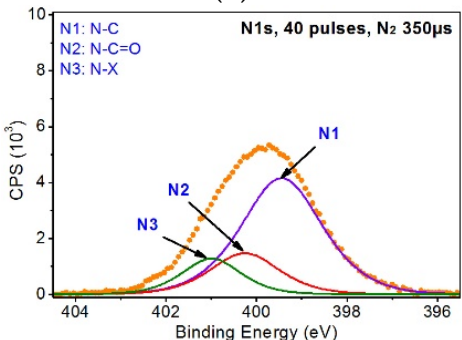

(h)

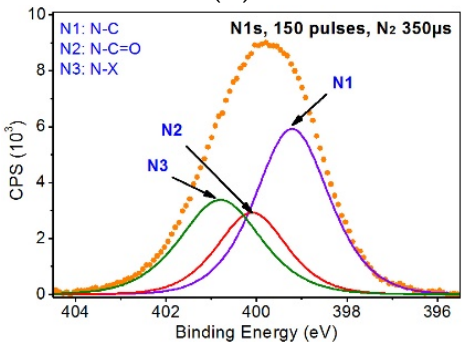

(k)

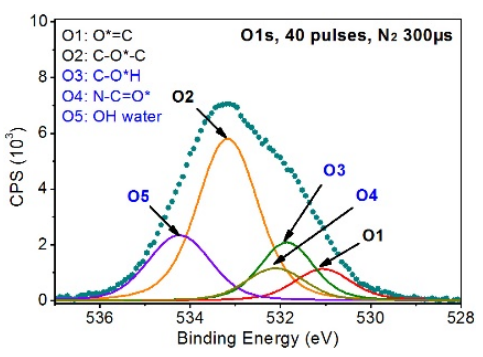

(c)

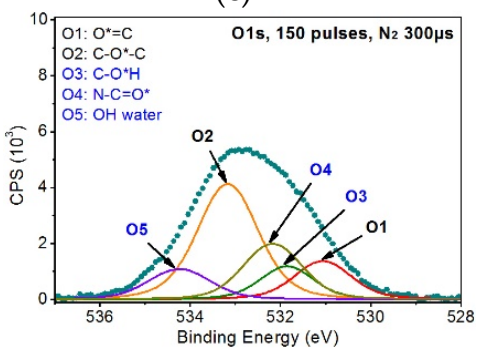

(f)

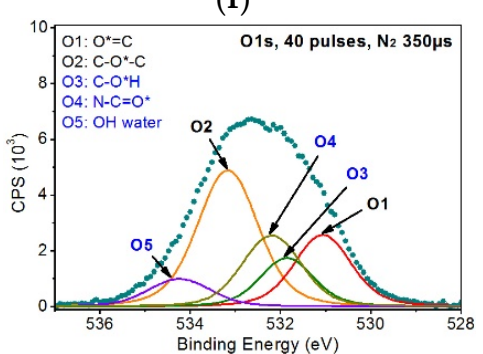

(i)

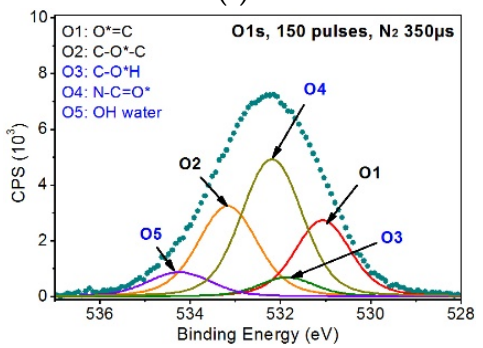

(1)

Figure 8. XPS spectra of modified PEEK: (a) C1s band for 40 pulses $\left(\mathrm{N}_{2} 300 \mu \mathrm{s}\right)$, (b) N1s band for 40 pulses ( $\left.\mathrm{N}_{2} 300 \mu \mathrm{s}\right)$, (c) O1s band for 40 pulses $\left(\mathrm{N}_{2} 300 \mu \mathrm{s}\right)$, (d) $\mathrm{C} 1 \mathrm{~s}$ band for 150 pulses $\left(\mathrm{N}_{2} 300 \mu \mathrm{s}\right)$, (e) N1s band for 150 pulses $\left(\mathrm{N}_{2} 300 \mu \mathrm{s}\right)$, (f) O1s band for 150 pulses $\left(\mathrm{N}_{2} 300 \mu \mathrm{s}\right)$, (g) C1s band for 40 pulses $\left(\mathrm{N}_{2} 350 \mu \mathrm{s}\right)$, (h) N1s band for 40 pulses $\left(\mathrm{N}_{2} 350 \mu \mathrm{s}\right)$, (i) O1s band for 40 pulses $\left(\mathrm{N}_{2} 350 \mu \mathrm{s}\right)$, (j) C1s band for 150 pulses $\left(\mathrm{N}_{2} 350 \mu \mathrm{s}\right)$, (k) N1s band for 150 pulses $\left(\mathrm{N}_{2} 350 \mu \mathrm{s}\right)$, (1) O1s band for 150 pulses $\left(\mathrm{N}_{2} 350 \mu \mathrm{s}\right)$.

The analysis of the samples modified with EUV radiation in the presence of nitrogen additionally assumed that the peaks in C1s and O1s bands would be tightly related to each other in terms of their percentage content. As a result, the content of the C5 peak is the same as the content of the N1 peak and the content of the $\mathrm{C} 7$ peak is equal to the content of both the $\mathrm{N} 2$ and $\mathrm{O} 4$ peaks as they are associated with the same chemical structures/functional groups. However, the N3 peak turned out to be much more difficult to interpret and, therefore, such an association could not be established. Nevertheless, the presence of this peak is certain, as indicated by the shape of the N1s band and the results of the analysis of the polymers containing nitrogen in their structure, which suggests that FWHM of the peaks in the N1s band should not exceed $2.1 \mathrm{eV}$. Taking the specificity of the modification 
process, it is highly probable that there can be even more peaks in the N1s band; however, the simplest model was developed for the analysis that properly reflects the chemical changes that took place.

Precise positions, FWHMs, and percentage contents of peaks from C1s, N1s, O1s bands for all the samples are listed in Table 1.

Table 1. Binding energy range, FWHM range, and atomic concentration of different functional groups for pristine PEEK and modified PEEK.

\begin{tabular}{|c|c|c|c|c|c|c|c|c|c|c|}
\hline $\begin{array}{l}\text { Symbol } \\
\text { of the } \\
\text { Peak }\end{array}$ & $\begin{array}{l}\text { Chemical } \\
\text { Group }\end{array}$ & $\begin{array}{c}\text { Position } \\
(\mathrm{eV})\end{array}$ & $\begin{array}{c}\text { FWHM } \\
(\mathrm{eV})\end{array}$ & $\begin{array}{l}\text { PEEK } \\
\text { (at.\%) }\end{array}$ & $\begin{array}{l}\text { PEEK } \\
\text { EUV40 } \\
\text { (at. } \%)\end{array}$ & $\begin{array}{c}\text { PEEK } \\
\text { EUV150 } \\
\text { (at.\%) }\end{array}$ & $\begin{array}{c}\text { PEEK } \\
\text { EUV40 } \\
\mathrm{N}_{2} 300 \\
\mu \mathrm{s} \\
\text { (at. } \% \text { ) }\end{array}$ & $\begin{array}{c}\text { PEEK } \\
\text { EUV150 } \\
\mathrm{N}_{2} 300 \\
\mu \mathrm{s} \\
\text { (at. } \% \text { ) }\end{array}$ & $\begin{array}{c}\text { PEEK } \\
\text { EUV40 } \\
\mathrm{N}_{2} 350 \\
\mu \mathrm{s} \\
\text { (at. } \%)\end{array}$ & $\begin{array}{c}\text { PEEK } \\
\text { EUV150 } \\
\mathrm{N}_{2} 350 \\
\mu \mathrm{s} \\
\text { (at. } \%)\end{array}$ \\
\hline $\mathrm{C} 1$ & $\mathrm{C}-\mathrm{C}=\mathrm{C}$ & 284.8 & 1.3 & 62.3 & 49.8 & 50.0 & 19.6 & 21.3 & 23.2 & 22.5 \\
\hline $\mathrm{C} 2$ & $\mathrm{C}^{*}-\mathrm{O}-\mathrm{C}^{*}$ & 286.4 & $1.6-1.7$ & 19.9 & 14.6 & 10.5 & 9.9 & 7.4 & 8.5 & 5.0 \\
\hline $\mathrm{C} 3$ & $\mathrm{C}=\mathrm{O}$ & 286.7 & $1.7-1.8$ & 4.0 & 2.3 & 1.1 & 0.9 & 1.2 & 2.1 & 2.0 \\
\hline $\mathrm{C} 4$ & $\mathrm{C}^{*}-\mathrm{COO}$ & 285.4 & $1.3-1.4$ & - & 17.2 & 22.8 & 46.0 & 37.7 & 26.8 & 22.2 \\
\hline C5 & $\mathrm{C}^{*}-\mathrm{N}$ & $286.3-286.4$ & 1.5 & - & - & - & 1.8 & 5.5 & 7.1 & 8.2 \\
\hline $\mathrm{C} 6$ & $\mathrm{O}-\mathrm{C}^{*}-\mathrm{O}$ & 287.3 & $1.4-1.5$ & - & 3.0 & 3.8 & 5.3 & 6.6 & 6.3 & 7.0 \\
\hline $\mathrm{C} 7$ & $\mathrm{~N}-\mathrm{C}^{*}=\mathrm{O}$ & $288.4-288.5$ & 1.5 & - & - & - & 1.0 & 1.7 & 2.2 & 3.8 \\
\hline $\mathrm{C} 8$ & $\mathrm{C}^{*}=\mathrm{O}(\mathrm{OH})$ & $288.8-288.9$ & 1.5 & - & 1.5 & 2.0 & 1.6 & 0.9 & 1.3 & 0.5 \\
\hline C9 & $\mathrm{C}^{*}-\mathrm{OON}$ & $289.3-289.5$ & 1.5 & - & - & - & 0.0 & 0.6 & 0.9 & 2.2 \\
\hline N1 & $\mathrm{N}^{*}-\mathrm{C}$ & $399.2-399.4$ & $1.9-2.1$ & - & - & - & 1.8 & 5.5 & 7.1 & 8.2 \\
\hline N2 & $\mathrm{N}^{*}-\mathrm{C}=\mathrm{O}$ & $400.0-400.2$ & $1.8-1.9$ & - & - & - & 1.0 & 1.7 & 2.2 & 3.8 \\
\hline N3 & $\mathrm{N}^{*}-\mathrm{x}$ & $400.8-401.0$ & $1.8-2.1$ & - & - & - & 0.8 & 1.4 & 1.6 & 5.2 \\
\hline O1 & $\mathrm{O}^{*}=\mathrm{C}$ & 531.1 & 1.5 & 4.0 & 2.3 & 1.1 & 0.9 & 1.2 & 2.1 & 2.0 \\
\hline $\mathrm{O} 2$ & $\mathrm{C}-\mathrm{O}^{*}-\mathrm{C}$ & 533.2 & 1.6 & 9.9 & 7.3 & 5.3 & 5.0 & 3.7 & 4.3 & 2.5 \\
\hline $\mathrm{O} 3$ & $\mathrm{C}-\mathrm{O} * \mathrm{H}$ & 531.9 & $1.4-1.5$ & - & 1.5 & 2.0 & 1.6 & 1.0 & 1.3 & 0.5 \\
\hline $\mathrm{O} 4$ & $\mathrm{~N}-\mathrm{C}=\mathrm{O}^{*}$ & $532.1-532.2$ & $1.5-1.6$ & - & - & - & 1.0 & 1.7 & 2.2 & 3.8 \\
\hline O5 & $\mathrm{OH}$ (water) & $534.2-534.5$ & $1.6-1.7$ & & 0.6 & 1.4 & 2.0 & 1.0 & 0.9 & 0.7 \\
\hline
\end{tabular}

The analysis assumed that the sum of all the peaks from all the bands is 100 at. $\%$ for a given sample.

As can be seen in Table 1, modification carried out leads to significant changes in the percentage content of functional groups coming from the pristine PEEK. The most explicit changes appear for the $\mathrm{C} 1$ peak, the percentage content of which lowers from 62.3 at. $\%$ for the pristine PEEK to 49.8 at. $\%$ and 50.0 at.\% for the PEEK treated with 40 EUV pulses and 150 EUV pulses, respectively. Much lower percentage content of the $\mathrm{C} 1$ peak was observed for the samples modified with EUV radiation in the presence of nitrogen. This percentage content is from 19.6 at.\% to 23.3 at. $\%$. The percentage contents of $\mathrm{C} 1$ observed for this group of samples are close to one another but are not correlated with the number of pulses and the valve opening time.

Similar changes in the percentage content were observed also for the chemical groups marked as $\mathrm{C} 2$ and $\mathrm{C} 3$ as well as for the peaks $\mathrm{O} 1$ and $\mathrm{O} 2$. In each of these cases modification leads to a decrease in the percentage content versus the pristine material. Their percentage content varies and depends on the parameters of a modification. However, similarly as in the case of $\mathrm{C} 1$, no explicit relation between the percentage content of the peaks, the number of pulses, and the valve opening time is observed.

Evident relation between the percentage contents and the parameters of modification is noticed for the samples irradiated with EUV in the presence of nitrogen. It is noticeable specifically for the C5, $\mathrm{C} 7$, and $\mathrm{C} 9$ peaks representing the chemical groups containing nitrogen atoms and correlated with the N1, N2, and N3 peaks in the N1s band as well as with the O4 peak in the O1s band in the model developed. Their percentage content increases with the increase in the number of pulses used and the valve opening time. In the N1s band, it is the N1 peak that has the highest percentage content in each 
sample modified. The maximum percentage content of this peak is noticed for the sample modified with 150 EUV pulses, for which the valve opening time is $350 \mu \mathrm{s}$.

In order to correctly fill the envelope of the $\mathrm{C} 1$ s and $\mathrm{O} 1$ s band, the $\mathrm{C} 4, \mathrm{C} 6, \mathrm{C} 8$ and $\mathrm{O} 3, \mathrm{O} 5$ peaks were also introduced that represent the functional groups containing the carbon-oxygen bond. For the sake of the analysis, the minimum number of the peaks appropriately describing the $\mathrm{C} 1 \mathrm{~s}$ and $\mathrm{O} 1 \mathrm{~s}$ bands was assumed. However, due to the random nature of the formation of new functional groups on the PEEK surface, the model developed may not include all the chemical structures that may arise as a result of the modification applied. This is the reason for which certain randomness is observed in the percentage contents of the $\mathrm{C} 1-\mathrm{C} 3$ and $\mathrm{O} 1-\mathrm{O} 2$ peaks coming from the pristine material.

Overall percentage contents of elements for the PEEK samples examined are listed in Table 2.

Table 2. The atomic concentration of carbon, nitrogen, and oxygen for unmodified and modified PEEK.

\begin{tabular}{|c|c|c|c|c|c|c|c|}
\hline Elements & $\begin{array}{l}\text { PEEK } \\
\text { (at.\%) }\end{array}$ & $\begin{array}{c}\text { PEEK } \\
\text { EUV40 } \\
\text { (at.\%) }\end{array}$ & $\begin{array}{c}\text { PEEK } \\
\text { EUV150 } \\
\text { (at.\%) }\end{array}$ & $\begin{array}{c}\text { PEEK } \\
\text { EUV40 } \\
\mathrm{N}_{2} 300 \mu \mathrm{s} \\
\text { (at.\%) }\end{array}$ & $\begin{array}{c}\text { PEEK } \\
\text { EUV150 } \\
\mathrm{N}_{2} 300 \mu \mathrm{s} \\
\text { (at.\%) }\end{array}$ & $\begin{array}{c}\text { PEEK } \\
\text { EUV40 } \\
\mathrm{N}_{2} 350 \mu \mathrm{s} \\
\text { (at.\%) }\end{array}$ & $\begin{array}{c}\text { PEEK } \\
\text { EUV150 } \\
\mathrm{N}_{2} 350 \mu \mathrm{s} \\
\text { (at. } \% \text { ) }\end{array}$ \\
\hline $\mathrm{C}$ & 86.1 & 88.3 & 90.2 & 86.0 & 82.9 & 78.4 & 73.3 \\
\hline $\mathrm{N}$ & - & - & - & 3.5 & 8.6 & 10.9 & 17.2 \\
\hline $\mathrm{O}$ & 13.9 & 11.7 & 9.8 & 10.5 & 8.5 & 10.8 & 9.5 \\
\hline
\end{tabular}

As can be seen in Table 2, the pristine PEEK contains 86.1 at.\% of carbon and 13.9 at. $\%$ of oxygen. Modification using only EUV radiation leads to a decrease in the percentage content of oxygen and therefore to an increase in the percentage content of carbon. An increase in the number of EUV pulses results in a decrease in the percentage content of oxygen to 11.7 at.\% for $40 \mathrm{EUV}$ pulses and 9.8 at.\% for 150 EUV pulses. As described previously, this causes changes in C1s and O1s envelopes and the appearance of new functional groups.

As can be seen in Table 2, the method of modification using EUV radiation in the presence of nitrogen that was used enables incorporating a vast number of nitrogen atoms into the polymer surface. The percentage content of nitrogen atoms depends on both the number of pulses used $(40,150)$ and the opening time of the valve from which nitrogen was injected (300 $\mu \mathrm{s}, 350 \mu \mathrm{s})$. The percentage content of nitrogen obtained ranges from 3.5 at.\% for EUV $40\left(\mathrm{~N}_{2} 300 \mu \mathrm{s}\right)$ to 17.2 at.\% for EUV $150\left(\mathrm{~N}_{2} 350 \mu \mathrm{s}\right)$. As can be noticed, the increase in the percentage content of nitrogen is not directly proportional to the number of pulses. However, extending the time of nitrogen injection of $50 \mu$ s results in a more than doubled increase in the percentage content of nitrogen in the modified samples. A thorough analysis of the N1s band also shows that no matter what the modification parameters are (number of pulses, valve opening time), the same chemical structures/functional groups appear and only their percentage content varies. No explicit relation between modification parameters and the percentage content of peaks in the N1s band was observed, though. This can be the effect of the stochastic character of the chemical changes that take place on the surface of samples during the modification process.

As for the proportion of oxygen in these samples, it is lower than for the pristine PEEK and slightly lower than for the samples treated with the same number of EUV pulses in the absence of nitrogen. The percentage content of oxygen in these samples is very similar and shows no correlation with the change in nitrogen at.\%. Theoretically, it would be expected that due to the modification the oxygen atoms would be replaced by nitrogen atoms. In fact, the percentage content of the nitrogen increases with the decrease in the percentage content of carbon. The final percentage contents of the oxygen for these samples, as well as for all the others, depends not only on the modification process itself, but also from the fact that just after the removal of the samples from the vacuum chamber, the empty bonds on the surface of the samples become saturated with oxygen atoms. 


\section{Conclusions}

In this paper, the influence of EUV irradiation and the combination of EUV irradiation and low-temperature nitrogen plasma on the physico-chemical properties of PEEK polymer was presented. It was found that due to the modification, the topography of the PEEK surfaces significantly changed. The micro- and nanometer-scale features, including characteristic conical structures, appeared on the PEEK surface, and an increase in the average surface roughness was observed (from $16.2 \mathrm{~nm}$ for pristine PEEK up to $115 \mathrm{~nm}$ for modified PEEK). The modification with the use of EUV pulses alone, and the modification by the simultaneous interaction of the EUV pulses and the nitrogen photoionized plasma, also dramatically affected the chemical composition of PEEK surfaces. Modification using only EUV radiation led to a decrease in the percentage content of oxygen, which increased the percentage content of carbon, and the appearance of the new chemical groups. On the other hand, modification with the use of EUV radiation in the presence of nitrogen resulted not only in the appearance of new functional groups but in the incorporation of a vast amount of nitrogen up to 17.2 at.\% as well. Therefore, the modification technique presented may be considered as a useful tool for surface activation of the PEEK polymer.

Author Contributions: Conceptualization, J.C.; Software, J.C. and B.B.; Analysis, J.C. and B.B.; Investigation, J.C.; Methodology, J.C., B.B., A.B., P.W., H.F.; Writing—original draft preparation, J.C.; writing-review and editing, Z.M., J.C., A.B., P.W., H.F.; Visualization, J.C., B.B., P.W., A.B. All authors have read and agreed to the published version of the manuscript.

Funding: This research was supported by the National Science Centre, Poland, grant agreement no. UMO-2016/23/B/ST7/00949, and partially by the National Science Centre, Poland, grant agreement no. UMO-2019/03/X/ST5/01643.

Conflicts of Interest: The authors declare no conflict of interest.

\section{References}

1. Ma, R.; Tang, S.; Tan, H.; Qian, J.; Lin, W.; Wang, Y.; Liu, C.; Wei, J.; Tang, T. Preparation, characterization, in vitro bioactivity, and cellular responses to a polyetheretherketone bioactive composite containing nanocalcium silicate for bone repair. ASC Appl. Mater. Interfaces 2014, 6, 12214-12225. [CrossRef]

2. Kobayashi, T.; Rikukawa, M.; Sanui, K.; Ogata, N. Proton-conducting polymers derived from poly(ether-etherketone) and poly(4-phenoxybenzoyl-1,4-phenylene). Solid State Ion. 1998, 106, $219-225$. [CrossRef]

3. Kurtz, S.M.; Devine, J.N. PEEK biomaterials in trauma, orthopedic, and spinal implants. Biomaterials 2007, 28, 4845-4869. [CrossRef]

4. Toth, J.M.; Wang, M.; Estes, B.T.; Scifert, J.L.; Seim, H.B.; Turner, A.S. Poletheretherketone as a biomaterial for spinal applications. Biomaterials 2006, 27, 324-334. [CrossRef] [PubMed]

5. Reisnger, B.; Fahrner, M.; Frischauf, I.; Yakunin, S.; Švorčík, V.; Fiedorowicz, H.; Bartnik, A.; Romanin, C.; Heitz, J. EUV micropatterning for biocompatibility control of PET. Appl. Phys. A 2010, 100, 511-516. [CrossRef]

6. Jacobs, T.; Declercq, H.; De Geyter, N.; Cornelissen, R.; Dubruel, P.; Leys, C.; Beaurain, A.; Payen, E.; Morent, R. Plasma surface modification of polylactic acid to promote interaction with fibroblasts. J. Mater. Sci. Mater. Med. 2013, 24, 469-478. [CrossRef]

7. Slepička, P.; Slepičková Kasálková, N.; Pinkner, A.; Sajdl, P.; Kolská, Z.; Švorčík, V. Plasma induced cytocompatibility of stabilized poly-L-lactic acid doped with graphene nanoplatelets. React. Funct. Polym. 2018, 131, 266-275. [CrossRef]

8. Ul Ahad, I.; Butruk, B.; Ayele, M.; Budner, B.; Bartnik, A.; Fiedorowicz, H.; Ciach, T.; Brabazon, D. Extreme ultraviolet (EUV) surface modification of polytetrafluoroethylene (PTFE) for control of biocompatibility. Nucl. Instrum. Methods Phys. Res. B 2015, 364, 98-107. [CrossRef]

9. Maitz, M.F. Applications of synthetic polymers in clinical medicine. Biosurf. Biotribol. 2015, 1, 161-176. [CrossRef] 
10. Czwartos, J.; Budner, B.; Bartnik, A.; Kasprzycka, W.; Fiedorowicz, H. Effect of photoionized plasma and EUV induced surface modification on physico-chemical properties and cytocompatibility of PLLA. Express Polym. Lett. 2020, 14, 1063-1077. [CrossRef]

11. Bai, J.; Ding, R.; Wang, Y.; Chen, T.; Xu, Q.; Feng, B.; Duan, K.; Zhi, W.; Weng, J.; Wang, J. Surface modification of polyetheretherketone by grafting amino groups to improve its hydrophilicity and cytocompatibility. Mater. Res. Express 2019, 6. [CrossRef]

12. Wang, W.; Luo, C.J.; Huang, J.; Edirisinghe, M. PEEK surface modification by fast ambient-temperature sulfonation for bone implant applications. J. R. Soc. Interface 2019, 16. [CrossRef]

13. Riveiro, A.; Soto, R.; Comesana, R.; Boutinguiza, M.; del Val, J.; Quintero, F.; Lusquinos, F.; Pou, J. Laser surface modification of PEEK. Appl. Surf. Sci. 2012, 258, 9437-9442. [CrossRef]

14. Wilson, A.; Jones, I.; Salmat-Zadeh, F.; Watts, J.F. Laser surface modification of poly(etheretherketone) to enhance surface free energy, wettability and adhesion. Int. J. Adhes. Adhes. 2015, 62, 69-77. [CrossRef]

15. Wang, S.; Deng, Y.; Yang, L.; Shi, X.; Yang, W.; Chen, Z. Enhanced antibacterial property and osteo-differentiation activity on plasma treated porous polyetheretherketone with hierarchical micro/nano-topography. J. Biomater. Sci. Polym. Ed. 2018, 29, 520-542. [CrossRef]

16. Briem, D.; Strametz, S.; Schröder, K.; Meenen, N.M.; Lehmann, W.; Linhart, W.; Ohl, A.; Rueger, M.J. Response of primary fibroblasts and osteoblasts to plasma treated polyetheretherketone (PEEK) surfaces. J. Mater. Sci. Mater. Med. 2005, 16, 671-677. [CrossRef] [PubMed]

17. Waser-Althaus, J.; Salamon, A.; Waser, M.; Podeste, C.; Kreutzer, M.; Pieles, U.; Müller, B.; Peters, K. Differentiation of human mesenchymal stem cells on plasma-treated polyetheretherketone. J. Mater. Sci. Mater. Med. 2014, 25, 515-525. [CrossRef]

18. Novotna, Z.; Reznickova, A.; Rimpelova, S.; Vesely, M.; Kolska, Z.; Svorcik, V. Tailoring of PEEK bioactivity for improved cell interaction: Plasma treatment in action. RSC Adv. 2015, 5, 41428-41436. [CrossRef]

19. Wiącek, A.E.; Terpiłowski, K.; Jurak, M.; Worzakowska, M. Effect of low-temperature plasma on chitosan-coated PEEK polymer characteristics. Eur. Polym. J. 2016, 78, 1-13. [CrossRef]

20. Gravis, D.; Poncin-Epaillard, F.; Coulon, J.-F. Correlation between the surface chemistry, the surface free energy and the adhesion of metallic coatings onto plasma-treated Poly(ether ether ketone). Appl. Surf. Sci. 2020, 501. [CrossRef]

21. Dupuis, A.; Ho, T.H.; Fahs, A.; Lafabrier, A.; Louarn, G.; Bacharouche, J.; Airoudj, A.; Aragon, E.; Chailan, J.-F. Improving adhesion of powder coating on PEEK composite: Influence of atmospheric plasma parameters. Appl. Surf. Sci. 2015, 357, 1196-1204. [CrossRef]

22. Fedel, M.; Micheli, V.; Thaler, M.; Awaja, F. Effect of nitrogen plasma treatment on the crystallinity and self-bonding of polyetheretherketone (PEEK) for biomedical applications. Polym. Adv. Technol. 2020, 31, 240-247. [CrossRef] [PubMed]

23. Bartnik, A.; Fiedorowicz, H.; Jarocki, R.; Kostecki, J.; Szczurek, M.; Wachulak, P.W. Laser-plasma EUV source dedicated for surface processing of polymers. Nucl. Instrum. Methoods Phys. Res. A 2011, 647, 125-131. [CrossRef]

24. Bartnik, A.; Skrzeczanowski, W.; Fiedorowicz, H.; Wachulak, P.; Fok, T. Low-temperature plasmas induced in nitrogen by extreme ultraviolet (EUV) pulses. Laser Part. Beams 2018, 36, 76-83. [CrossRef]

25. Bartnik, A.; Lisowski, W.; Sobczak, J.; Wachulak, P.; Budner, B.; Korczyc, B.; Fiedorowicz, H. Simultaneous treatment of polymer surface by EUV radiation and ionized nitrogen. Appl. Phys. A 2012, 109, $39-43$. [CrossRef]

26. Bäerle, D. Laser Processing and Chemistry, 4th ed.; Springer: Berlin, Germany, 2011.

27. Lippert, T.; Dickinson, T. Chemical and Spectroscopic Aspects of Polymer Ablation: Special Features and Novel Directions. Chem. Rev. 2003, 103, 453-485. [CrossRef]

28. Murthy, N.S.; Prabhu, R.D.; Martin, J.J.; Zhou, L.; Headrick, R.L. Self-assembled and etched cones on laser ablated polymer surfaces. J. Appl. Phys. 2006, 100, 023538:1-023538:12. [CrossRef]

29. Bartnik, A.; Fiedorowicz, H.; Jarocki, R.; Kostecki, J.; Rakowski, R.; Szczurek, A.; Szczurek, M. Micro- and Nanoprocessing of Polymers Using a Laser Plasma Extreme Ultraviolet Source. Acta Phys. Pol. A 2010, 117, 384-390. [CrossRef]

30. Bartnik, A.; Fiedorowicz, H.; Jarocki, R.; Kostecki, J.; Szczurek, M. PMMA and FEP surface modifications induced with EUV pulses in two selected wavelength ranges. Appl. Phys. A 2010, 98, 61-65. [CrossRef] 
31. Bartnik, A.; Fiedorowicz, H.; Jarocki, R.; Kostecki, J.; Szczurek, M.; Bilinski, A.; Chernyayeva, O.; Sobczak, J.W. Physical and chemical modifications of PET surface using a laser-plasma EUV source. Appl. Phys. A 2010, 99, 831-836. [CrossRef]

32. Bartnik, A.; Fiedorowicz, H.; Burdyńska, S.; Jarocki, R.; Kostecki, J.; Szczurek, M. Combined effect of EUV irradiation and acetone treatment on PET surface. Appl. Phys. A 2011, 103, 173-178. [CrossRef]

33. Hopp, B.; Bor, Z.; Homolya, E.; Mihalik, E. Investigation of conical structures created by ArF excimer laser irradiation of polycarbonate. Appl. Surf. Sci. 1997, 109, 232-235. [CrossRef]

(C) 2020 by the authors. Licensee MDPI, Basel, Switzerland. This article is an open access article distributed under the terms and conditions of the Creative Commons Attribution (CC BY) license (http://creativecommons.org/licenses/by/4.0/). 